\title{
Optimization of Convective Heat Transfer Model of Cold Storage with Cylindrical Pin Finned Evaporator Using Taguchi S/N Ratio and ANOVA Analysis
}

\author{
${ }^{1}$ Dr. N. Mukhopadhyay, ${ }^{2}$ Tapan Mondal \\ ${ }^{1}$ Assistant Professor, Department of Mechanical Engineering, Jalpaiguri Government Engineering College, \\ Jalpaiguri-735102, West Bengal, India \\ ${ }^{2}$ Post Graduate scholar, Department of Mechanical Engineering, Jalpaiguri Government Engineering College, \\ Jalpaiguri-735102, West Bengal, India
}

\begin{abstract}
In this work design of experiment have been used to optimize various control factors of a cold storage for reducing the use of electrical energy to overcome the energy crisis and reduce the cost price of the commodities that are kept. In this situation if the maximum heat energy $(\mathrm{Q})$ is absorbed by the evaporator inside the cold room through convective heat transfer process in terms of -heat transfer due to convection and heat transfer due to condensation, more energy has to be wasted to maintain the evaporator space at the desired temperature range of 2-6 degree centigrade. Taguchi orthogonal array have been used as a design of experiments. The control factors are Area of the evaporator with fin (A), temperature difference of the evaporator space (dT), and relative humidity inside the cold room (RH). Different amount of heat gains in the cold room for different set of test runs have been taken as the output parameter. The objective of this work is to find out the optimum setting of the control factors or design parameters so as the heat absorb in the cold room by the evaporator will be maximum. The Taguchi $\mathrm{S} / \mathrm{N}$ ratio analysis have used as an optimization technique. Larger the better type $\mathrm{S} / \mathrm{N}$ ratio have used for calculating the optimum level of control parameters, because it is a maximization problem. Analysis of variance ANOVA was also performed on the test results to find out the significant control factors.

KEYWORDS - Taguchi L9 orthogonal array, convective heat transfer co-efficient, cylindrical pin fin area and arrangement, S/N ratio analysis, ANOVA analysis.
\end{abstract}

\section{INTRODUCTION}

Cold storages form the most important element for proper storage and distribution of vide variety of perishables like fruits, vegetables and fish or meat processing. India is the largest producer of fruits and second largest producer of vegetables in the world. In spite of that per capita availability of fruits and vegetables is quite low because of post harvest losses that account for about 25 to $30 \%$ of production. Besides, quality of a sizable quantity of products also deteriorates by the time it reaches the consumer. As India is the second largest producer $(45,343,600$ tonnes at 2015) of potato after China and largest producer of the ginger (702000 metric tonnes i.e. $34.6 \%$ of the world total) without these there are many kind of food commodities are produce in our country so demand for cold storages have been increasing rapidly over the past couple of decades so that food commodities can be uniformly supplied all through the year and food items are prevented from perishing. Besides the role of stabilizing market prices and evenly distributing both on demand basis and time basis, the cold storage industry provide other advantages and benefits to both the farmers and the consumers. The farmers get the opportunity to get a good return of their hard work. On the consumer sides they get the perishable commodities with lower fluctuation of price. Very little theoretical and experimental studies are being reported in the journal on the performance enhancement of cold storage. Energy crisis is one of the most important problems the world is facing nowadays. With the increase of cost of electrical energy operating cost of cold storage storing is increasing which forces the increased cost price of the commodities that are kept. So it is very important to make cold storage energy efficient or in the other words reduce its energy consumption. Thus the storage cost will eventually come down. In case of conduction we have to minimize the leakage of heat through wall but in convection maximum heat should be absorbed by refrigerant to create cooling uniformity thought out the evaporator space. If the desirable heat is not absorbed by tube or pipe refrigerant then temp of the refrigerated space will be increased, which not only hamper the quality of the product which has been stored there but reduces the overall performance of the plant. That's why a mathematical modelling is absolutely necessary to predict the performance. In this paper we have 
proposed a theoretical heat transfer model of convective heat transfer model development of a cold storage using Taguchi L9 orthogonal array. Area of the evaporator with fin (A), Temperature difference (dT), Relative Humidity (RH)are the basic variables and three ranges are taken each of them in the model development. A graphical interpretation from the model justifies the reality.

\section{MODEL DEVELOPMENT}

\section{Range And Parameter Selection}

The length, breath and heightof each chamber of cold storage are $87.5 \mathrm{~m}, 34.15 \mathrm{~m}$ and $16.77 \mathrm{~m}$ respectively.

The three values of area of the evaporator with fin (A) of evaporator space are $8.253 \mathrm{~m}^{2}, 10.314 \mathrm{~m}^{2}$ and $14.628 \mathrm{~m}^{2}$ respectively. The three values of temperature difference (dT) of evaporator space are $2,5 \& 8$ centigrade respectively. The three values of relative humidity $(\mathrm{RH})$ of evaporative space are $0.85,0.90 \& 0.95$ respectively.

Table no. 1 Control factors with their range

\begin{tabular}{|l|l|l|l|l|l|}
\hline \multirow{2}{*}{ Notation } & Factors & Unit & \multicolumn{2}{|l|}{ Levels } \\
\cline { 4 - 6 } A & $\begin{array}{l}\text { Area of the } \\
\text { evaporator } \\
\text { with fin }\end{array}$ & $\mathrm{m}^{2}$ & 8.253 & 10.314 & 14.628 \\
\hline DT & $\begin{array}{l}\text { Temperature } \\
\text { Difference }\end{array}$ & ${ }^{\circ} \mathrm{C}$ & 2 & 5 & 8 \\
\hline RH & $\begin{array}{l}\text { Relative } \\
\text { Humidity }\end{array}$ & $\%$ & 0.85 & 0.90 & 0.95 \\
\hline
\end{tabular}

In this study, Mohitnagar cold storage (Jalpaiguri) $\&$ Teesta cold storage has been taken as a model of observation.

\section{Heat Calculation}

In this study heat transfer from evaporating space to refrigerant (which are in tube Basic equation for heat transfer

$\mathrm{Q}_{\mathrm{T}}=\mathrm{Q}_{\text {conv }}+\mathrm{Q}_{\text {condensation }}$.

$\mathrm{Q}_{\text {conv }}=\mathrm{Ah}_{\mathrm{c}} \mathrm{dT} \& \mathrm{Q}_{\text {condensation }}=\mathrm{Ah}_{\mathrm{m}}(\mathrm{RH}) \mathrm{h}_{\mathrm{fg} \text {. }}$ [3]

Here $\mathrm{Q}_{\text {conv }}=$ heat transfer due to convection $\& \mathrm{Q}_{\text {condensation }}=$ heat transfer due to condensation $\&$ $\mathrm{Q}_{\mathrm{T}}=$ Total heat transfer or absorb heat into refrigerant.

$\left.\mathrm{Q}_{\mathrm{T}}=\mathrm{Ah}_{\mathrm{c}} \mathrm{dT}+\mathrm{Ah} \mathrm{h}_{\mathrm{m}} \mathrm{RH}\right) \mathrm{h}_{\mathrm{fg}}$ or, $\mathrm{Q}_{\mathrm{T}}=\left[\mathrm{Ah}_{\mathrm{c}} \mathrm{dT}\right]+\left[\left(\mathrm{h}_{\mathrm{c}} / 1.005\right) \cdot \mathrm{A} \cdot \mathrm{RH} \cdot \mathrm{h}_{\mathrm{fg}}\right]$

[As we know, $h_{\mathrm{c}} / \mathrm{h}_{\mathrm{m}}=\mathrm{c}_{\mathrm{p}}(\mathrm{Le})^{2 / 3}$

$$
\begin{aligned}
& \text { or, } \mathrm{h}_{\mathrm{c}} / \mathrm{h}_{\mathrm{m}}=1.005(1)^{2 / 3} \\
& \text { or, } \left.\mathrm{h}_{\mathrm{c}}=\mathrm{h}_{\mathrm{m}}\right]
\end{aligned}
$$

or, $\mathrm{Q}_{\mathrm{T}}=\mathrm{Ah}_{\mathrm{c}}\left[\mathrm{dT}+\left(\mathrm{RH} . \mathrm{h}_{\mathrm{fg}}\right) / 1.005\right]$

or, $\mathrm{Q}_{\mathrm{T}}=\mathrm{A} \cdot \mathrm{h}_{\mathrm{c}}\left(\mathrm{dT}+\mathrm{RH} \cdot \mathrm{h}_{\mathrm{fg}}\right)$

The heat transfer equation due to area of the evaporator with fin $(\mathbf{A})$, temperature difference $(\mathbf{d T}) \&$ relative humidity $\mathrm{RH})$ is $\mathbf{Q}_{\mathrm{T}}=\mathbf{A} \mathbf{h}_{\mathbf{c}}(\mathbf{d T}+\mathbf{2 4 9 0} \mathbf{R H})$.

Here, $\mathbf{A}=$ surface area of tubes in evaporator with fin

$. \mathbf{h}_{\mathbf{c}}=$ convective heat transfer co-efficient.

$\mathbf{h}_{\mathbf{m}}=$ convective mass transfer co-efficient,

$\mathbf{h}_{\mathbf{f g}}=$ latent heat of condensation of moisture $2490 \mathrm{KJ} / \mathrm{Kg}-\mathrm{K}$.

$\mathbf{C}_{\mathbf{p}}=$ specific heat of air $1.005 \mathrm{KJ} / \mathrm{Kg}-\mathrm{K}$.

$\mathbf{L e}=$ Lewis number for air it is one.

Now we calcutate the value of convective heat transfer co-efficient $\left(h_{c}\right)$,

We know,

$\mathbf{N u}=\frac{\text { Convective heat transfer }}{\text { Conductive heat transfer }}=\left(\mathbf{h}_{\mathbf{c}} * \mathbf{L}\right) / \mathbf{k}$

Where:

$\mathrm{Nu}=$ Nusselt number or pipe) only being considered.The transfer heat evaporating space to refrigerant are calculated in terms of Area of the evaporator with fin(A), temperature difference (dT) \& relative humidity $\mathrm{RH})$. Only convection heat transfer effect is being considered in this study. ..(1)[8] 
$\mathrm{hc}=$ convective heat transfer coefficient

$\mathrm{k}=$ thermal conductivity, $\mathrm{W} / \mathrm{mK}$

$\mathrm{L}=$ characteristic length, $\mathrm{m}$

The convection heat transfer coefficient is then defined as following:

$\mathbf{h}_{\mathbf{c}}=\frac{\mathrm{Nu} * \mathrm{~K}}{\mathrm{~L}}$

The Nusselt number depends on the geometrical shape of the heat sink and on the air flow. For convection on flat isothermal plate the formula is natural given in table

Table no- 2

Nusselt number formula.

\begin{tabular}{|l|l|l|l|}
\hline & Vertical fins & & Horizontal fins \\
\hline Laminar flow & $\mathrm{Nu}=0.59 * \mathrm{Ra}^{0.25}$ & Upward laminar flow & $\mathrm{Nu}=0.54 * \mathrm{Ra}^{0.25}$ \\
\hline Turbulent flow & $\mathrm{Nu}=0.14 * \mathrm{Ra}^{0.33}$ & Downward laminar flow & $\mathrm{Nu}=0.27 * \mathrm{Ra}^{0.25}$ \\
\hline & & Turbulent flow & $\mathrm{Nu}=0.14 * \mathrm{Ra}^{0.33}$ \\
\hline
\end{tabular}

Where:

$\mathbf{R a}=\mathbf{G r} * \mathbf{P r}$

The Rayleigh number(Ra) defined in terms of Prandtl number (Pr) and Grashof number (Gr).

If , $\mathrm{Ra}<10^{9}$ the heat flow is laminar,

while $\mathrm{Ra}>106$ the flow is turbulent.

\section{Grashof number $(\mathbf{G r})$ :}

$\mathbf{G r}=\frac{g * L^{3} * \alpha *(T a-T p)}{\eta^{2}} \quad$ [for natural convective heat transfer from a cold body]

Where:

- $\mathrm{g}=$ acceleration of gravity $=9.81, \mathrm{~m} / \mathrm{s} 2$

- $\mathrm{L}=$ longer side of the fin $=30$ foot $=9.144 \mathrm{~m}$

$-\alpha=$ air thermal expansion coefficient. For gases, is the reciprocal of the temperature in Kelvin:

$\alpha=\frac{1}{\mathrm{Ta}}, 1 / \mathrm{K}=(1 / 275.15) \mathrm{K}$

$-\mathrm{T}_{\mathrm{p}}=$ Plate temperature, $=272.15 \mathrm{~K}$

$-\mathrm{T}_{\mathrm{a}}=$ Air temperature $=275.15 \mathrm{~K}$

$-\eta=$ air kinematic viscosity $=13.39 * 10^{-6} \mathrm{~m}^{2} / \mathrm{s}$ [at air temp. $=275.15 \mathrm{~K} \&$ air pressure $=1 \mathrm{bar}$ ]

$\mathrm{Gr}=\frac{9.81 *(9.144)^{3} \cdot\left(\frac{1}{275.15}\right) *(275.15-272.15)}{\left(13 . .99 \cdot 10^{-6}\right)^{2}}$

$$
\text { or, } \mathrm{Gr}=4.56 * 10^{11}
$$

Prandtl number (Pr):

$\operatorname{Pr}=\frac{\mu^{*} c p}{K}$

Where:

- $\mu$ = air dynamic viscosity, is $1.725 * 10^{-5} \mathrm{~kg} / \mathrm{m} . \mathrm{s}$ at $275.15 \mathrm{~K}$

- $\mathrm{cp}=$ air specific heat $=1005 \mathrm{~J} /(\mathrm{Kg} * \mathrm{~K})$ for dry air

- $\mathrm{k}=$ air thermal conductivity $=0.0244 \mathrm{~W} /(\mathrm{m} * \mathrm{~K})$ at $275.15 \mathrm{~K}$

$\operatorname{Pr}=\frac{1.725 \cdot 10^{-5} * 1005}{0.0244}$

Or, $\operatorname{Pr}=0.711$

So,

$\mathbf{R a}=\mathbf{G r} * \mathbf{P r}$

$\mathrm{Ra}=4.56 * 10^{11} * 0.711$

$\mathrm{Ra}=3.24 * 10^{11}$ 
As, $\mathrm{Ra}>10^{9}=$ Turbulent flow

So, Nustle Number for turbulent flow,

$\mathrm{Nu}=0.14 * \mathrm{Ra}^{0.33}$

$\mathrm{Nu}=0.14 *\left(3.24 * 10^{11}\right)^{0.33}$

$\mathrm{Nu}=880.25$

So, Convective Heat Transfer co-efficient $\left(\mathrm{h}_{\mathrm{c}}\right)$ :-

$\mathbf{h}_{\mathbf{c}}=\frac{880.25 * 0.0244}{9.144}$

or, $\mathbf{h}_{\mathbf{c}}=\mathbf{2 . 3 5}$

So, The final Heat Transfer equation when we replace the $h_{c}$ in equation (1) we get,

$\mathrm{Q}_{\mathrm{T}}=2.35^{*} \mathrm{~A}(\mathrm{dT}+\mathbf{2 4 9 0} \mathrm{RH})$

(3)

Table 3 shows the L9 OA combinations among various control factors.

\begin{tabular}{|l|l|l|l|}
\hline & \multicolumn{3}{|c|}{ Control Factors } \\
\hline Sl. No. & A & dT & RH \\
\hline $\mathbf{1}$ & 1 & 1 & 1 \\
\hline $\mathbf{2}$ & 1 & 2 & 2 \\
\hline $\mathbf{3}$ & 1 & 3 & 3 \\
\hline $\mathbf{4}$ & 2 & 1 & 2 \\
\hline $\mathbf{5}$ & 2 & 2 & 1 \\
\hline $\mathbf{6}$ & 2 & 3 & 3 \\
\hline $\mathbf{7}$ & 3 & 1 & 3 \\
\hline $\mathbf{8}$ & 3 & 2 & 1 \\
\hline $\mathbf{9}$ & 3 & 3 & 2 \\
\hline
\end{tabular}

Table 4 L9 OA combinations among various control factors Observation Table

\begin{tabular}{|l|l|l|l|l|}
\hline Test Runs & A & dT & RH & Q \\
\hline 1 & 8.253 & 2 & 0.85 & 41087.35 \\
\hline 2 & 8.253 & 5 & 0.90 & 43560.16 \\
\hline 3 & 8.253 & 8 & 0.95 & 46032.96 \\
\hline 4 & 10.314 & 2 & 0.90 & 54365.61 \\
\hline 5 & 10.314 & 5 & 0.95 & 57455.94 \\
\hline 6 & 10.314 & 8 & 0.85 & 51493.42 \\
\hline 7 & 14.628 & 2 & 0.95 & 81384.71 \\
\hline 8 & 14.628 & 5 & 0.85 & 72928.26 \\
\hline 9 & 14.628 & 8 & 0.90 & 77311.17 \\
\hline
\end{tabular}

In the above table Area (A), Temperature difference (dT), Relative humidity (RH) of the cold storage have been experimentally observed within the range of maximum, minimum and average mid value and thereafter heat transfer quantity $(\mathrm{Q})$ is being calculated theoretically

\section{Cylindrical Pin-Fin}

The configuration of the pin is shown in Figure 1. The cross section is a $5 \mathrm{~mm}$ circle. This diameter was considered as a reference length scale.

If we consider " $\mathrm{H}$ " as the height of the cylinder, the surface area can easily calculated from

the following formulas:

Surface Area $=$ Areas of top and bottom + Area of the side

Surface Area $=2($ Area of top $)+(\text { perimeter of top })^{*}$ height

Surface area of single cylindrical pin fin $=$
The calculated surface area was kept constant for all different fin morphologies. This ensured that the contact surface areas between fluid and fins were equal in all cases and the effect of

fin morphology could be studied more easily. Also the height of the pin $(\mathrm{H})$ were kept

constant for the rectangular pin-fin too. This was impossible to do for the drop-shaped pin-fin 
due to practical matters.

We know,

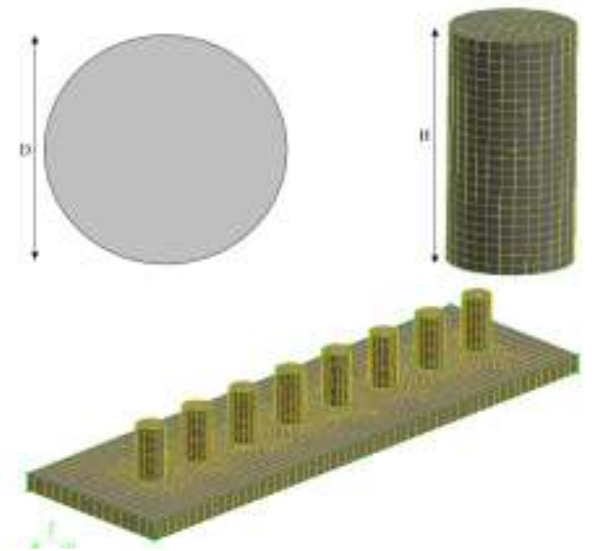

Fig.1 Configuration of Cylindrical pin fin

Where,

$$
\begin{aligned}
& A=A_{b}+A_{f} \\
& A_{b}=\pi^{*} r^{2} L^{2} \\
& A_{f}=\left[2 \pi\left(D^{2} / 4\right)+(\pi * D) H\right] * n * N
\end{aligned}
$$

$\mathrm{r}=$ Radius of bare tube $=0.038 \mathrm{~m}$

$\mathrm{L}=$ Length of bare tube $=1 \mathrm{~m}$

$\mathrm{D}=$ Diameter of cylindrical Pin fin $=0.005 \mathrm{~m}$

$\mathrm{H}=$ Height of cylindrical Pin fin $=0.02 \mathrm{~m}$

$\mathrm{n}=$ Number of bare tube $=1$

$\mathrm{N}=$ Number of cylindrical Pin fin

\section{Chain ordering Pin fin arrangement :}

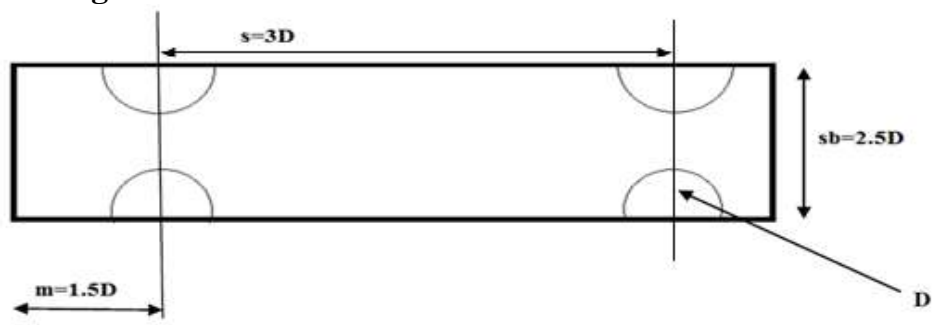

Where,

Fig.2 Arrangment of Pin fin

$\mathrm{D}=$ Diameter of fin

$\mathrm{S}=$ Longitudal Fin Spacing $(\mathrm{S}=3 \mathrm{D})$

$\mathrm{S}_{\mathrm{b}}=$ Breadth wise fin spacing $(\mathrm{S}=2.5 \mathrm{D})$

$\mathrm{m}=\operatorname{Margin}(\mathrm{m}=1.5 \mathrm{D})$

\section{S/N RATIO}

III. RESULTS AND DISCUSSIONS

The signal to noise ratios $(\mathrm{S} / \mathrm{N})$, which are $\log$ functions of desired output, serve as the objective functions for optimization, help in data analysis and the prediction of the optimum results. There are 3 types of $\mathrm{S} / \mathrm{N}$ ratios are availablenamely smaller the better, larger the better \& nominal is the best. In this problem we both use larger-the-better types $\mathrm{S} / \mathrm{N}$ ratio.

In case of conduction process we use larger-the-better type $\mathrm{S} / \mathrm{N}$ ratio to maximize the heat flow from inside of the cold room to outside through the evaporator. Ratio to maximize the heat transfer in the evaporator space of the cold room.

For conduction process

Smaller-the-better

This is expressed as $-(\mathrm{S} / \mathrm{N})=-10 \log 10$ (mean of sum of squares of measured data) 
This is usually the chosen $\mathrm{S} / \mathrm{N}$ ratio for all the undesirable characteristics like "defects" for which the ideal value is zero. When an ideal value is finite and its maximum or minimum value is defined (like the maximum purity is $100 \%$ or the maximum temperature is $92 \mathrm{~K}$ or the minimum time for making a telephone connection is $1 \mathrm{sec}$ ) then the difference between the measured data and the ideal value is expected to be as small as possible.

Thus, the generic form of $\mathrm{S} / \mathrm{N}$ ratio becomes$(\mathrm{S} / \mathrm{N})=-10 \log 10$ mean of sum of squares of (measured-ideal) data $\}$

\section{For convection and condensation process}

\section{Larger-the-better}

For calculating $\mathrm{S} / \mathrm{N}$ ratio for larger the better for maximum heat transfer, the equation is

$\mathrm{SN}_{\mathrm{i}}=-10 \log \left[\sum\left\{1 /\left(\mathrm{Q}_{\mathrm{i}}\right)^{2}\right\} / \mathrm{n}\right]$

Where $n=$ number of trials in a row

$\mathrm{Q}_{\mathrm{i}}=$ calculated value in the test run or row.

Trial number $=\mathrm{i}$

$\mathrm{SN}_{\mathrm{i}}=\mathrm{S} / \mathrm{N}$ ratio for respective result

For experiment no-1

SN1 $=-10 \log \left[\Sigma\left\{1 /(41087.35)^{2}\right\} / 1\right]=92.274$ Where, $Q 1=41087.35 \& n=1$

For experiment no-2

$\mathrm{SN} 2=-10 \log \left[\Sigma\left\{1 /(43560.16)^{2}\right\} / 1\right]=92.782$ Where, Q2=43560.16 \& $n=1$

For experiment no-3

SN3 $=-10 \log \left[\Sigma\left\{1 /(46032.96)^{2}\right\} / 1\right]=93.261$ Where, Q3=46032.96\& $n=1$

For experiment no-4

SN4 $=-10 \log \left[\Sigma\left\{1 /(54365.61)^{2}\right\} / 1\right]=94.706$ Where, Q4=54365.61\& $n=1$

For experiment no-5

SN5 $=-10 \log \left[\Sigma\left\{1 /(57455.94)^{2}\right\} / 1\right]=95.187$ Where, Q5=57455.94 \& $n=1$

For experiment no-6

SN6 $=-10 \log \left[\Sigma\left\{1 /(51493.42)^{2}\right\} / 1\right]=94.235$ Where, Q6=51493.42 \& $n=1$

For experiment no-7

SN7 $=-10 \log \left[\Sigma\left\{1 /(81384.71)^{2}\right\} / 1\right]=98.211$ Where, Q7=81384.71 \& $n=1$

For experiment no-8

SN8 $=-10 \log \left[\Sigma\left\{1 /(72928.26)^{2}\right\} / 1\right]=97.258$ Where, Q8=72928.26 \& $n=1$

For experiment no-9

SN9 $=-10 \log \left[\sum\left\{1 /(77311.17)^{2}\right\} / 1\right]=97.765$ Where, Q9=77311.17 \& $n=1$

Table 5 S/N Ratio Larger the better

\begin{tabular}{|c|c|c|c|c|c|c|c|c|}
\hline \multirow{3}{*}{$\begin{array}{l}\text { Exp. } \\
\text { No. }\end{array}$} & \multicolumn{6}{|c|}{ Parameter } & \multirow{3}{*}{$\begin{array}{l}\text { Heat } \\
\text { Transfer } \\
(\mathrm{KJ})\end{array}$} & \multirow{3}{*}{$\begin{array}{l}\text { S/N } \\
\text { Ratio } \\
\text { Larger } \\
\text { The } \\
\text { Better }\end{array}$} \\
\hline & \multirow{2}{*}{\multicolumn{3}{|c|}{$\begin{array}{l}\text { Combination } \\
\text { Control Parameter }\end{array}$}} & \multicolumn{3}{|c|}{ Control Parameter } & & \\
\hline & & & & \multirow{2}{*}{$\begin{array}{l}\begin{array}{l}\text { Area } \\
\left(\mathrm{m}^{2}\right)\end{array} \\
8.253\end{array}$} & \multirow{2}{*}{$\begin{array}{l}\text { Temperature } \\
\text { difference }\left(0_{c}\right)\end{array}$} & \multirow{2}{*}{$\begin{array}{l}\text { Relative } \\
\text { Humidity (\%) }\end{array}$} & & \\
\hline 1 & 1 & 1 & 1 & & & & 41087.35 & 92.274 \\
\hline 2 & 1 & 2 & 2 & 8.253 & 5 & 0.90 & 43560.16 & 92.782 \\
\hline 3 & 1 & 3 & 3 & 8.253 & 8 & 0.95 & 46032.96 & 93.261 \\
\hline 4 & 2 & 1 & 2 & 10.314 & 2 & 0.90 & 54365.61 & 94.706 \\
\hline 5 & 2 & 2 & 3 & 10.314 & 5 & 0.95 & 57455.94 & 95.187 \\
\hline 6 & 2 & 3 & 1 & 10.314 & 8 & 0.85 & 51493.42 & 94.235 \\
\hline 7 & 3 & 1 & 3 & 14.628 & 2 & 0.95 & 81384.71 & 98.211 \\
\hline 8 & 3 & 2 & 1 & 14.628 & 5 & 0.85 & 72928.26 & 97.258 \\
\hline 9 & 3 & 3 & 2 & 14.628 & 8 & 0.95 & 77311.17 & 97.765 \\
\hline
\end{tabular}

\section{Overall mean of $\mathrm{S} / \mathrm{N}$ ratio}

The calculation of overall mean is done by the following process:-

A11 = Mean of low level values of Area

$\mathrm{A} 11=(\mathrm{SN} 1+\mathrm{SN} 2+\mathrm{SN} 3) / 3=(92.274+92.782+93.261) / 3=92.7723$

A21 $=$ Mean of medium level values of Area

$\mathrm{A} 21=(\mathrm{SN} 4+\mathrm{SN} 5+\mathrm{SN} 6) / 3=(94.706+95.187+94.235) / 3=94.7093$

A31 $=$ Mean of high level values of Area 
A31 $=($ SN7 + SN8+ SN9) $/ 3=(98.211+97.258+97.765) / 3=97.7447$

$\mathrm{dT} 12=$ Mean of low level values of Temperature difference

$\mathrm{dT} 12=(\mathrm{SN} 1+\mathrm{SN} 4+\mathrm{SN} 7) / 3=(92.274+94.706+98.211) / 3=95.0637$

dT22 $=$ Mean of medium level values of Temperature difference

$\mathrm{dT} 22=(\mathrm{SN} 2+\mathrm{SN} 5+\mathrm{SN} 8) / 3=(92.782+95.187+97.258) / 3=95.0757$

dT32 $=$ Mean of high level values of Temperature difference

dT32 $=(\mathrm{SN} 3+\mathrm{SN} 6+\mathrm{SN} 9) / 3=(93.261+94.235+97.765) / 3=95.087$

RH13 = Mean of low level values of Relative humidity

$\mathrm{RH} 13=(\mathrm{SN} 1+\mathrm{SN} 6+\mathrm{SN} 8) / 3=(92.274+94.235+97.258) / 3=94.589$

RH23 $=$ Mean of medium level values of Relative humidity

RH23 $=($ SN2 +SN4+ SN9 $) / 3=(92.782+94.706+97.765) / 3=95.0843$

RH33 = Mean of high level values of Relative humidity

$\mathrm{RH} 33=(\mathrm{SN} 3+\mathrm{SN} 5+\mathrm{SN} 7) / 3=(93.261+95.187+98.211) / 3=95.553$

Table 6 Overall mean of S/N Ratio (Response Table for Signal to Noise Ratios Larger is better)

\begin{tabular}{|c|c|c|c|c|}
\hline Level & \multicolumn{3}{|c|}{ Average S/N Ratio by Factor Level } & \multirow{2}{*}{$\begin{array}{l}\text { Overall Mean of } \\
\text { S/N Ratio }\left(\mathrm{SN}_{0}\right)\end{array}$} \\
\hline & $\operatorname{Area}\left(\mathrm{m}^{2}\right)$ & $\begin{array}{l}\text { Temperature } \\
\text { Difference }\left(0_{c}\right)\end{array}$ & $\begin{array}{l}\text { Relative } \\
\text { Humidity }(\%)\end{array}$ & \\
\hline Low & 92.7723 & 95.0637 & 94.589 & \multirow{5}{*}{95.0754} \\
\hline Medium & 94.7093 & 95.0757 & 95.0843 & \\
\hline High & 97.7447 & 95.087 & 95.553 & \\
\hline $\begin{array}{l}\text { Delta=larger- } \\
\text { smaller }\end{array}$ & 4.9724 & 0.0233 & 0.964 & \\
\hline Rank & 1 & 2 & 3 & \\
\hline
\end{tabular}

Mean S/N ratio vs Area, temperature difference and relative humidity figure.

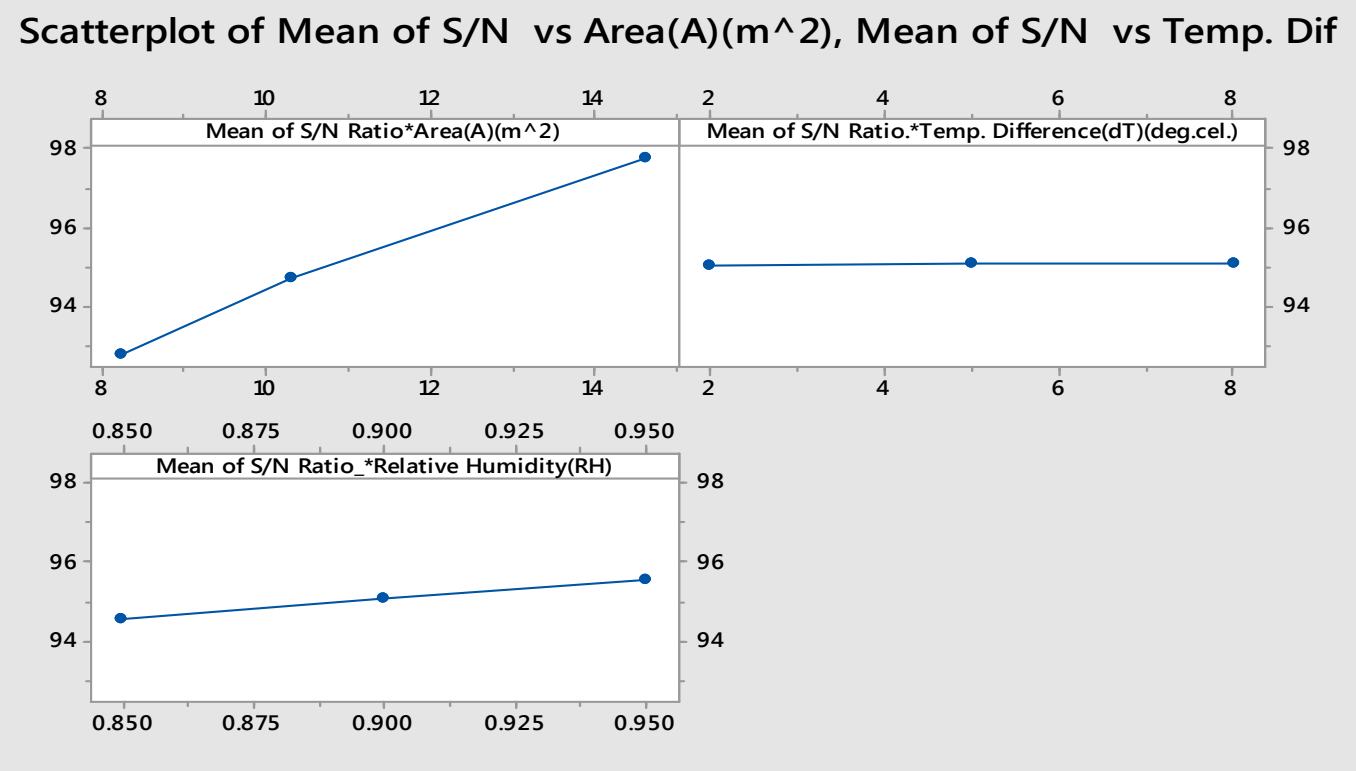

Fig. No. 3

\section{Analysis Of Variance (Anova) Calculation}

The test runs results were again analysed using ANOVA for identifying the significant factors and their relative contribution on the output variable. Taguchi method can not judge and determine effect of individual parameters on entire process while percentage contribution of individual parameters can be well determined using ANOVA.

Effect of each parameter can be determined by subtraction of each value of table no. 10 to the overall average of $\mathrm{S} / \mathrm{N}$ ratio (95.0754).After subtraction, the effect of each parameter obtained as follows:- 
Table 7: Effect of each parameter

\begin{tabular}{|l|l|l|l|}
\hline & $\begin{array}{l}\text { Area } \\
\left(\mathbf{m}^{\wedge} \mathbf{2}\right)\end{array}$ & $\begin{array}{l}\text { Temparature } \\
\text { Difference }\left({ }^{\mathbf{0}} \mathbf{C}\right)\end{array}$ & $\begin{array}{l}\text { Relative } \\
\text { Humidity } \mathbf{( \% )}\end{array}$ \\
\hline Low & -2.3031 & -0.0117 & -0.4864 \\
\hline Medium & -0.3661 & 0.0003 & 0.0089 \\
\hline High & 2.6693 & 0.0116 & 0.4776 \\
\hline
\end{tabular}

$\mathrm{SS}=$ Sum of square of each parameter air velocity $=\Sigma\left(\mathrm{V}_{\mathrm{ij}}-\mathrm{SN}_{\mathrm{O}}\right)^{2} *_{\mathrm{n}}$

$\mathrm{V}_{\mathrm{ij}}=$ Average $\mathrm{S} / \mathrm{N}$ ratio values from table 11 for each parameter (low, medium and high level)

$\mathrm{SN}_{0}=$ Overall mean of $\mathrm{S} / \mathrm{N}$ ratio $=3$

$\mathrm{SS}_{\text {Area }}$ evaporator $=\left[\left(-2.3031^{2}\right) * 3+(-\right.$

$\left.\left.0.3661^{2}\right) * 3+\left(2.6693^{2}\right) * 3\right]$

$=15.9128+0.4021+21.3755$

$=37.6904$

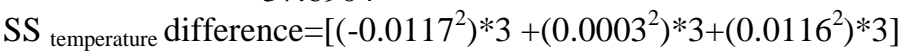

$=0.00041067+0.00000027+0.00040368$

$=0.00081462$

$\mathrm{SS}_{\text {Relative }}$ humidity $=\left[\left(-0.4864^{2}\right) * 3+\left(0.0089^{2}\right) * 3+\left(0.4776^{2}\right) * 3\right]$

$=0.7098+0.00023763+0.6843$

$=1.39433763$

Total sum of square $(\mathrm{TSS})=\left[\left(\mathrm{SN}_{\mathrm{i}}\right)^{2}\right]-\left[\left(\Sigma \mathrm{SN}_{\mathrm{i}}\right)^{2} / 9\right]$

$\mathrm{SN}_{\mathrm{i}}=\mathrm{S} / \mathrm{N}$ ratio values for each experiment

$\mathrm{i}=$ varies from $1 \ldots . .9$

$=\left[(92.274)^{2}\right.$

$+(92.782)^{2}+(93.261)^{2}+(94.706)^{2}+(95.187)^{2}+$

$(94.235)^{2}+$

$\left.(98.211)^{2}+(97.258)^{2}+(97.765)^{2}\right]-\left[(95.0754)^{2} / 9\right]$

$=39.0844332$

Sum of squared error $(\mathrm{SSE})=\mathrm{TSS}-\Sigma\left(\mathrm{SS}_{\text {Area }}+\mathrm{SS}_{\text {Temperature difference }}+\mathrm{SS}_{\text {Relative humidity }}\right)$

$$
\begin{aligned}
& =39.08443322-(37.6904+0.00081462+1.39433763) \\
& =0.00111903
\end{aligned}
$$

$\operatorname{dof}_{\text {total }}=$ total no. of experiment -1

$$
=9-1=8
$$

Dof $_{\text {Area }}=$ no. of level -1

$=3-1=2$

Dof $\mathrm{femperature} \mathrm{difference}_{\text {teno }}$ of level -1

$$
=3-1=2
$$

Dof $f_{\text {Relative humidity }}=$ no. of level -1

$$
=3-1=2
$$

Dof $_{\text {error }}=\operatorname{dof}_{\text {total }}-\left(\sum\right.$ dof $_{\text {Area }}+$ dof $_{\text {temperature difference }}+$ dof $\left._{\text {relativehumidity }}\right)$

$$
=8-(2+2+2)=2
$$

Mean square error $(\mathrm{MSE})=\mathrm{SS}_{\text {each factor }} /$ dof $_{\text {each factor }}$

$\mathrm{F}$ value $=\mathrm{MSE}_{\text {each factor }} / \mathrm{SSE}$

Another term appeared in the ANOVA table is percentage contribution of each factor. The formula for percentage contribution $=\left(\frac{\text { sum of square of factor }}{\text { total sum of squres }}\right) \times 100$

\begin{tabular}{|c|c|c|c|c|c|c|c|}
\hline Source & Notation & $\begin{array}{l}\text { Degrees of } \\
\text { Freedom }\end{array}$ & Sum of Squares & $\begin{array}{l}\text { Mean } \\
\text { Squares } \\
\end{array}$ & F Ratio & P Value & $\begin{array}{l}\% \\
\text { Contribution }\end{array}$ \\
\hline A & $\begin{array}{l}\text { Area of the Bear tube \& } \\
\text { Fin }\end{array}$ & 2 & 1768975312 & 884487656 & 970.13 & 0.001 & 96.4145 \\
\hline $\mathrm{dT}$ & Temperature Difference & 2 & 1463279 & 731640 & 0.80 & 0.555 & 0.07975 \\
\hline $\mathrm{RH}$ & Relative Humidity & 2 & 62498289 & 31249144 & 34.27 & 0.028 & 3.4063 \\
\hline Error & & 2 & 1823439 & 911720 & & & 0.09938 \\
\hline Total & & 8 & 1834760319 & & & & 100 \\
\hline
\end{tabular}

The tests run data in were again analysed using ANOVA at $95 \%$ confidence level $(\alpha=.05)$ for identifying the significant factors and their relative contribution on the output variable.

Table 8 The analysis was carried out in MINITAB software. The following table shows ANOVA table 
The above calculations suggest that the area of the Evaporator has the largest influence with a contribution of $96.4145 \%$. Next is relative

\section{CONCLUSION}

In this work study Taguchi method of design of experiment has been applied for optimizing the control parameters so as to increase heat transfer rate evaporating space to evaporating level. From the analysis of the results obtained following conclusions can be drawn-

1. From the Taguchi $\mathrm{S} / \mathrm{N}$ ratio graph analysis the optimal settings of the cold storage are Area of the Evaporator (A) $14.628\left(\mathrm{~m}^{2}\right)$, Temperature difference $(\mathrm{dT}) 2\left({ }^{\circ} \mathrm{c}\right)$ and Relative humidity (RH) 0.95 in percentage. This optimality has been proposed out of the range of [A (8.253, $10.314,14.628)$, dT $(2,5,8)$, RH $(0.85,0.90$, 0.95)].So, increase the evaporator Area is most important.

2. ANOVA analysis indicates Area of evaporator (A) is the most influencing control factor on Q and it is near about $96.4145 \%$.Next is relative humidity $3.4063 \%$ contribution

3. Results obtained both from Taguchi $\mathrm{S} / \mathrm{N}$ ratio analysis and the multiple regression analysis are also bearing the same trend.

4. The proposed model uses a theoretical heat convection model through cold storage using multiple regression analysis.

5. Taguchi L9 orthogonal array has used as design of experiments. The results obtained from the $\mathrm{S} / \mathrm{N}$ ratio analysis and ANOVA are close in values. Both have identified Area of the Evaporator (A) is the most significant control parameter followed by relative humidity (RH), and temperature difference (dT).

\section{REFERENCE}

\section{Journal Papers:}

[1]. Mälardalen University Press Licentiate Theses No. 88 "OPTIMAL PIN FIN HEAT EXCHANGER SURFACE” Hamid Nabati 2008

[2]. Iterative calculation of the heat transfer coefficient by D.Roncati (Progettazione Ottica Roncati, via Panfilio, 17 - 44121 Ferrara)

[3]. Dr. N. Mukhopadhyay-A Theoretical Comparative Study of Heat Load Distribution Model of a Cold Storage. International Journal of Scientific \& Engineering Research, Volume 6, Issue 2, February-2015 516 ISSN 2229-5518.

[4]. Dr. N. Mukhopadhyay- Optimization of Different Control Parameters of a Cold Storage using Taguchi Methodology,AMSE humidity with $3.4063 \%$ contribution and temperature difference has lowest contribution of $0.07975 \%$.

JOURNALS -2014-Series: Modelling D; Vol. 36; $\mathrm{N}^{\circ}$ 1; pp 1-9, Submitted July 2014; Revised Jan. 12, 2015; Accepted Feb. 20, 2015; www.ijera.com.

[5]. Dr. N. Mukhopadhyay-Theoretical Convective Heat Transfer Model Development of Cold Storage Using Taguchi Analysis.IJERAISSN : 2248-9622, Vol. 5, Issue 1, ( Part -6) January 2015, pp.13-17

[6]. Dr. N.Mukhopadhyay-Theoretical Convective Heat Transfer Model Development of Cold Storage Using Taguchi Analysis.ISSN:2248-9622, Vol.5,Issue 1,(part-6)January2015; www.ijera.com.

[7]. The effect of fin spacing and material on the performance of a heat sink with circular pin fins Department of Mechanical Engineering, Indian Institute of Technology Guwahati, Guwahati, Assam, India

[8]. Theoretical Convective Heat Transfer Model Developement of Cold Storage Using Taguchi Analysis. Dr.N.Mukhopadhyay , Suman Debnath; www.ijera.com.

Books:

[9]. ASHRAE Handbook of Fundamentals, 1993.

[10]. Process heat transfer by DONAL Q. KERN (M $\mathrm{M}_{\mathrm{C}}$ GRAW-HILL).

[11]. Heat and Mass Transfer; Yunus A. Cengel;Third Edition.

[12]. Fundamentals of Signal-to-Noise Ratio (SNR) by Christopher M Collins

[13]. Signal to Noise Ratio for Quality Evaluation by Genechi Taguchi

\section{Chapters in Books:}

[14]. Condenser and Evaporator-Version I ME IIT Kharagpur Lesson 22

\section{Website:}

[15]. www.engineeringtoolbox.com 